\title{
MENTORIAS SPOT: OPORTUNIDADE DE ORIENTAÇÃO PROFISSIONAL PARA INICIATIVAS EMPREENDEDORAS
}

Roberta Sodré Costa Leite ${ }^{1}$

Patricia Viveiros De Castro Krakauer²

Marcello Vinícius Dória Calvosa ${ }^{3}$

\footnotetext{
${ }^{1}$ Centro Universitário Campo Limpo Paulista / Unifaccamp

${ }^{2}$ Centro Universitário Campo Limpo Paulista (UNIFACCAMP)

${ }^{3}$ Universidade Federal Rural do Rio de Janeiro
} 


\title{
MENTORIAS SPOT: OPORTUNIDADE DE ORIENTAÇÃO PROFISSIONAL PARA INICIATIVAS EMPREENDEDORAS
}

Resumo: Uma das dificuldades enfrentadas por empreendedores da atualidade é a mortalidade precoce das empresas. A mentoria pode ser usada como um recurso estratégico e eficaz, em programas de apoio ao empreendedor, mas ainda há indefinições em alguns dos seus aspectos, especialmente no que tange a conceituação da atividade. $\mathrm{O}$ objetivo deste trabalho foi o de apresentar a conceitualização de mentoria spot, identificando suas vantagens e desvantagens, além de sua operacionalização. A pesquisa tem natureza exploratória, com abordagem qualitativa, e foram utilizadas entrevistas semiestruturadas com doze mentores e doze mentorados, e assim, pode-se constatar que o conceito de mentoria spot é vago e desconhecido para a maioria dos respondentes. Foram identificadas e analisadas as vantagens, desvantagens e a operacionalização das mentorias spot no universo das startups, propondo-se assim, um framework.

Palavras-chave: Mentoria. Startup. Mentoria Spot.

\section{Introdução}

A temática da presente pesquisa versa sobre a Mentoria Spot, apresentando-a como uma oportunidade de orientação profissional para iniciativas empreendedoras. O interesse por essa investigação nasceu da percepção prática de uma das presentes autoras que organiza rodadas de mentorias em programas de incubadoras no estado de São Paulo e percebeu que há uma carência prática, no que tange a operacionalização de mentorias e uma lacuna teórica sobre o que seja a mentoria spot, sendo que atualmente é comumente oferecida por atores do ecossistema e empreendedores para as startups.

O apoio dado para os empreendedores das startups pode ocorrer de várias formas, sendo: através de diversas pessoas, instituições e capitais. Contudo, para satisfazer os interesses deste estudo, o foco da pesquisa foi centrado e pautado na variável 'pessoas', especificamente no processo de mentoria. Isto se deu pelo fato de ser a mentoria um método que encoraja o desenvolvimento humano, mediante o qual uma das partes investe seu tempo, energia e conhecimento pessoal para prestar assistência ao crescimento e talento de outrem, para o desenvolvimento do indivíduo, principalmente o iniciante, dentro da organização (SHEA, 2001).

Segundo Pinho (2014) e Silva (2010) há outros processos de orientação profissional nas empresas além do mentoring, como o coaching e o couseling que são também processos que ajudam os profissionais a alinharem seus objetivos e metas, capacitando-lhes para gerar resultados diferenciados, contribuindo para o desenvolvimento profissional do indivíduo.

\begin{abstract}
O termo mentoring é usado nas organizações para destacar alguém que lida com a orientação de um indivíduo por meio de técnicas que o auxiliem a um excelente desempenho. Os processos de mentoring, ..., ocorrem com profissionais que já estão em seu campo de atuação. Essa função pode ser exercida por uma pessoa da própria empresa ou de fora dela. No que se refere ao termo counseling, pode-se dizer que é ligado à área clínica, que se caracteriza como um aconselhamento psicológico. Assim, é encontrada uma analogia com o processo de OP, o que não se distancia da prática do orientador de um aconselhamento de carreira. (PINHO, 2014, p. 10).
\end{abstract}

As mentorias passaram a ter evidência no Brasil dada a importância que o empreendedorismo tem na economia do nosso país e, em especial, em startups que são negócios de maior impacto. As empresas nascentes ou em fase startup caracterizam-se por serem jovens, com pouco tempo de existência e apresentarem estruturas organizacionais simples, com poycos 
especialização funcional e foco no desenvolvimento de produtos, onde o crescimento se dá de forma consideravelmente alta (TAKAKI, 2015).

Diante do panorama atual enfrentado pelos empreendedores - mortalidade precoce, dificuldade para inovar, momento de crise entre outros aspectos (SEBRAE, 2018) - a utilização das mentorias poderá apoiá-los, ajudando na complexidade do momento e nos problemas que ocorrem nas etapas de crescimento. No ambiente da economia criativa, ou seja, ambiente onde a maioria das startups reside, a velocidade dos acontecimentos é maior que no ambiente dos negócios tradicionais e, por esse motivo, a mentoria ganha importância ao possibilitar que o empreendedor busque conhecimento numa rede de mentores amplamente divulgada no ecossistema para a solução da demanda (ARANHA, 2016).

Destaca-se que a mentoria envolve uma intensa relação entre uma pessoa mais madura e experiente, no caso um mentor, que proporciona assistência a um colega menos experiente e mais jovem, e no caso o mentorado, buscando elevar seu desenvolvimento pessoal e profissional (HEZLETT; GIBSON, 2007).

A despeito de sua importância nesse contexto, podendo ser usada como uma ferramenta estratégica e eficaz em programas de treinamento e desenvolvimento, ainda há indefinições em alguns aspectos centrais da mentoria, como a própria investigação empírica sobre a avaliação do seu processo (SILVA, 2010). Apesar de existirem materiais práticos disponíveis na internet, ou seja, não é mentoria spot uma terminologia inédita, ao se consultar o Google Scholar em outubro/18, percebeu-se que dos quatro mil artigos encontrados ao se utilizar as palavras-chave 'mentoring, mentoria e startups', nenhum possuía o foco em startups, justificando a presente pesquisa. Assim, apesar de não ser um termo inédito, a mentoria spot tem sido utilizada pelas instituições de fomento e carece de estudos teóricos a respeito.

Destaca-se que não é objetivo da pesquisa cunhar um termo para esse tipo específico de orientação, mas sim, conceituar a prática e organizar o processo. Diante do exposto, a presente pesquisa busca responder a seguinte questão: $\mathrm{O}$ que é a mentoria spot no universo das startups? E tem como objetivos: apresentar a conceitualização de mentoria spot; identificar e analisar as vantagens e desvantagens da mentoria spot; e propor um framework para sua operacionalização.

Esta pesquisa poderá contribuir com instituições de fomento que utilizem a mentoria spot para startups, de forma a ter a sua operacionalização formalizada em um framework, facilitando e uniformizando sua aplicação.

\section{$2 \quad$ Referencial Teórico}

\subsection{Formas Clássicas de Orientação Profissional}

A orientação profissional de indivíduos ou empresas - na figura representante de um empresário ou mesmo da formação jurídica cultural de um grupo formador de opinião - pode englobar um ou mais das três principais formas clássicas de orientação: o Mentoring, o Counseling e o Coaching (CALVOSA, 2018) que serão apresentadas nos próximos itens.

\subsubsection{Mentoria}

O conceito de mentoria não é novo, a origem do conceito de mentoria remonta a mitologia grega, onde Odisseia de Homero retrata a figura do mentor que protegia o jovem Telêmaco, na ida a Tróia, quando Odisseu (Ulisses), Rei de Ithaca foi para frente de batalha e conferiu os cuidados de sua família à figura do escravo de nome Mentor, que trabalhava como mestre e conselheiro do seu filho Telêmaco e forneceu conhecimento e direcionamento (RAGINS; KRAM, 2007; CUNHA; DIAS, 2010; BELLODI; MARTINS, 2005). É definida por Bellodi e Martins (2005. p. 53) como "uma modalidade especial de relação de ajuda em que, essencialmente, uma pessoa mais experiente acompanha de perto orienta e estimula um 
Segundo o Conselho Regional de Administração de São Paulo (CRA SP) através da Resolução GEC/01 de 19/05/2009 conceitua-se mentoring como "uma relação orientativa, sistemática ou não, onde o mentor com base em suas experiências e maturidade (profissional e pessoal), indica linhas de atuação, facilitando, estimulando e acompanhando o desenvolvimento do indivíduo/cliente" (RAMALHO, 2010, p. 2).

O Mentoring é um processo de orientação profissional pautado na confiança e admiração que o mentorado (agente recebedor de tal processo de orientação) possui em relação a um mentor, uma espécie de arquétipo. Para o autor, na prática, é uma espécie de aconselhamento aberto e genérico, com base em reflexões e transferência de experiências, com a intenção de deixar o mentorado mais apto e qualificado, por meio de metáforas autoaplicáveis e individualizadas, no formato de 'lições de vida' (CALVOSA, 2017).

Silva (2010) aponta que os processos de mentoria, geralmente, têm seu universo de aplicabilidade restrito a profissionais já inseridos no mundo do trabalho há algum tempo e as funções do mentor tanto podem ser desempenhadas por um consultor externo, quanto por um profissional experiente, pertencente aos quadros da empresa.

Para Calvosa (2017) alguns dos benefícios do Mentoring são: mentorados mais abertos às mudanças e flexíveis; com estímulo à criatividade; com um olhar mais contemplativo da vida; um acirramento de inovação no ambiente de trabalho e maior harmonia entre o desenvolvimento pessoal e profissional.

Quatro são os tipos de mentoria divididas em algumas categorias. Oliveira Neto e Souza-Silva (2018) realizaram uma revisão da literatura nacional e internacional e obtiveram vários tipos de mentoria que poderão ser analisados no Quadro 2. Os autores afirmam que a mentoria tradicional é quando o mentor está hierarquicamente muito acima do mentorando. O step ahead mentor é um indivíduo que está apenas em um nível hierárquico acima do mentorado. E no peer mentoring, o mentor está no mesmo nível hierárquico que o mentorado. Ele funciona, porém, como um conselheiro, pois, normalmente possui mais tempo de empresa que o mentorando, reunindo, assim, mais conhecimentos, habilidades e experiências sobre determinados procedimentos, tarefas e rotinas. Pode também ser virtual, também denominada de e-mentoring, na qual meios eletrônicos são utilizados na comunicação entre mentor e mentorado. No modelo tradicional a mesma ocorre presencialmente, face a face.

\section{Quadro 2: Tipos de Mentorias e suas Categorias}

\begin{tabular}{|c|c|c|}
\hline Tipos de Mentoria & Categorias & Referencial Teórico \\
\hline $\begin{array}{c}\text { Em Relação à Rede de } \\
\text { Relacionamentos }\end{array}$ & $\begin{array}{c}\text { Receptiva, Tradicional, } \\
\text { Oportunista e Empreendedora }\end{array}$ & Higgins e Kram (2001); Dobrow et. al. (2012) \\
\hline $\begin{array}{c}\text { Em Relação à } \\
\text { Formalização }\end{array}$ & Formal e Informal & $\begin{array}{c}\text { Ragins e Cotton (1999); Ragins; Cotton e Miller } \\
\text { (2000) }\end{array}$ \\
\hline Em Relação à Hierarquia & $\begin{array}{c}\text { Tradicional, Peer Mentoring, } \\
\text { Step ahead Mentoring }\end{array}$ & $\begin{array}{c}\text { Kram e Isabella (1985); Ensher, Thomas e } \\
\text { Murphy (2001) }\end{array}$ \\
\hline Em Relação ao Contexto & Tradicional e Virtual (e- \\
mentoring) & $\begin{array}{c}\text { Ensher, Heun e Blanchard (2003); Hamilton e } \\
\text { Scandura (2003) }\end{array}$ \\
\hline
\end{tabular}

Fonte: Oliveira Neto e Souza-Silva (2018, p.66).

Para Vergara (2010) existem dois tipos de mentoria: a mentoria natural (informal) e a intencional (formal). A mentoria natural ou informal ocorre naturalmente, sem planejamento, exercendo influência sobre o mentorado de forma a ajudá-lo a alcançar seus objetivos, a realizar seus sonhos, compreender situações, a lidar com desafios. Já a mentoria intencional ou formal é mais planejada e desenvolvida com a assistência ou intervenção da organização, havendo início, meio e fim.

DOI: 10.14211/xi-egepe-117997 
Sobre os mentores, são geralmente definidos como indivíduos com grande experiência e conhecimento, sendo responsáveis por dar suporte e promover a mobilidade ascendente de carreira para seus mentorados (KRAM, 1988), sendo atores importantes que dão aos empreendedores ganhos de tempo e aprendizado, atuando também como aceleradores do aprendizado (MASON; ROSS, 2014; CAMPOS, 2015; ABREU, 2016).

Higgins e Kram (2001, p. 268) apontam que primeiro os mentores podem oferecer funções de carreira que envolvem uma gama de comportamentos que ajudam os protegidos a "se libertarem de suas cordas" e a prepará-los para avançar hierárquicamente dentro de suas organizações. Em segundo lugar, os autores apontam que os mentores podem fornecer funções psicossociais que constrõem confiança, intimidade e relacionamento interpessoal que são vínculos no relacionamento e podem incluir comportamentos que aumentem o nível de crescimento profissional e pessoal, identidade, autoestima e autoeficácia (HIGGINS; KRAM, 2001).

Em seus primeiros trabalhos, Kram (1985) observou que as funções de carreira dependem da posição do mentor e de sua influência na organização, enquanto que as funções psicossociais dependem da qualidade dos vínculos emocionais e dos apegos psicológicos na relação com o mentorado. Pesquisas subseqüentes descobriram que as funções de carreira e as funções psicossociais constituem duas dimensões relativamente independentes dos comportamentos de mentoria (RAGINS; KRAM, 2007).

\subsubsection{Coaching}

Segundo Oliveira-Silva et al. (2018) o coaching, embora ainda recente no Brasil, apresenta-se na atualidade como uma área de atuação diversa, emergente e amplamente difundida, sendo uma perspectiva de treinamento e desenvolvimento de competências que popularizou-se atingindo uma amplitude de serviços.

Conforme Rich (2015) a técnica de coaching foi validada e é amplamente utilizada desde o início dos anos 1980, mas foi a partir do ano 2000 que houve o aumento do interesse sobre o tema e a técnica no Brasil. O processo ocorreu devido aos profissionais interessados em se capacitar como coaches, pelos clientes interessados em usufruir da técnica, pelo interesse na característica extremamente focal do processo, e pela expressividade social e financeira dada aos pertencentes à classe desses profissionais.

Uma das primeiras hipóteses é que coaching tenha surgido em uma cidade da Hungria chamada Kocs, entre os séculos XV e XVI. A palavra coaching inicialmente esteve relacionada ao transporte, mais precisamente ao tipo de carruagem coberta húngara, sendo posteriormente associada, tanto o transporte, como o treinador que conduziam as pessoas a um determinado lugar ou objetivo (COX; BACHKIROVA; CLUTTERBUCK, 2014; MILARÉ; YOSHIDA, 2009).

Três definições sobre o termo 'coaching' têm sido utilizadas para retratar essa nova fase do empreendedorismo digital e serão apresentadas no Quadro 3.

\section{Quadro 3: Conceitos e definições contemporâneas do coaching}

\begin{tabular}{|c|c|}
\hline AUTOR/ANO & DEFINIÇÃO \\
\hline $\begin{array}{l}\text { Marques- } \\
\text { Lopes }(2014, \\
\text { p. } 1)\end{array}$ & $\begin{array}{l}\text { Coaching é um processo de desenvolvimento humano, pautado em diversas ciências como: } \\
\text { Psicologia, Sociologia, Neurociências, Programação Neurolinguística, e que usa de técnicas da } \\
\text { Administração de Empresas, Gestão de Pessoas e do universo dos esportes para apoiar pessoas e } \\
\text { empresas no alcance de metas, no desenvolvimento acelerado e, em sua evolução contínua. }\end{array}$ \\
\hline $\begin{array}{l}\text { Cox, } \\
\text { Bachkirova; } \\
\text { Clutterbuck } \\
\text { (?014 n 1) }\end{array}$ & $\begin{array}{l}\text { O coaching é um processo de desenvolvimento humano que envolve o uso de interações } \\
\text { estruturadas e focadas e de estratégias, ferramentas e técnicas apropriadas para promover } \\
\text { mudanças desejáveis e sustentáveis, visando o benefício do indivíduo e, potencialmente, de } \\
\text { outrns stakoholdors } 10.14211 / \text { xi-egepe-117997 }\end{array}$ \\
\hline
\end{tabular}


É o processo de desenvolvimento pessoal ou profissional, que é conduzido por meio de um

Fonte: Elaborado pela autora (2018).

Segundo Campos, Capelle e Silva (2017) o processo de coaching é mais diretivo, positivo, sendo um processo que envolve a descoberta das habilidades, através do estabelecimento de metas de curto, médio e longo prazo. O processo para ser desenvolvido depende muito do envolvimento do coachee. Esta exigência é parte primordial da elaboração do coaching. Responsabilizar-se pela tomada de decisão e ter autonomia são as tarefas principais no desenvolvimento de coaching.

Araújo (2012) define o coach como um profissional que promove um serviço de apoio ao cliente com o objetivo de auxiliá-lo a alcançar seu sucesso, buscando trabalhar ainda mais com a sua subjetividade, entendendo a sua dinâmica e o seu padrão de funcionamento, auxiliando-o a seguir o melhor caminho para a realização de seus objetivos.

Nesta pesquisa, o conceito do autor Marques (2018) foi considerado como norteador.Os autores apontam que os processos de mentoring e coaching são buscados pelas organizações para eliminar ou amenizar o abismo que existe nas práticas e vivências dos profissionais de gerações diferentes e, portanto; há diferenciações entre mentoring e coaching que vão além da aplicabilidade de cada método.

O mentoring pode ser caracterizado como um treinamento interno de baixo ou nenhum custo financeiro para a organização. Em contrapartida, o coaching demanda um alto investimento financeiro da empresa. Além disso, o mentoring é uma via de mão dupla, em que tanto o mentor quanto o aprendiz são ativos no processo de ensino e aprendizagem. Já o coaching demanda distanciamento do coach para o coachee, caracterizando um atendimento, não um treinamento (CAMPOS; CAPELLE; SILVA; 2017. p. 290).

Para Milaré e Yoshida (2007) o coaching é um processo individual e personalizado para cada executivo coachee visando à mudança de atitudes, desenvolvimento de habilidades em liderança e definição de metas a serem atingidas e estratégias a serem utilizadas, preparando o executivo para tarefas futuras ou para assumir algum cargo, entre demais possibilidades.

\subsubsection{Counseling}

O Counseling é um processo orientado para a aprendizagem, que ocorre geralmente em um ambiente interativo, com o objetivo de ajudar uma pessoa a aprender mais sobre si mesmo, e se tornar um membro efetivo da sociedade (UNESCO, 1999).

O processo de Counseling sempre é direcionado de um indivíduo para outro indivíduo, diferente do Coach que pode tratar com um grupo inteiro de uma vez ou de um Mentor, que poderá ter dois ou mais mentorados em uma mesma reunião de compartilhamento de experiências ou divagações sobre algum objeto de observação ou de análise (CALVOSA, 2017).

O Counseling dará mais elementos para uma tomada de decisão pessoal do próprio aconselhado, enquanto o Coaching terá o foco no desenvolvimento de habilidades e mudanças de atitudes. O Mentoring terá como objetivo introduzir uma visão de mundo no orientado (CALVOSA, 2017).

Silva (2010) afirma que em relação ao counseling há uma notável singularidade nesta estratégia de ação em relação ao mentoring e ao coaching. O termo counseling é uma palavra

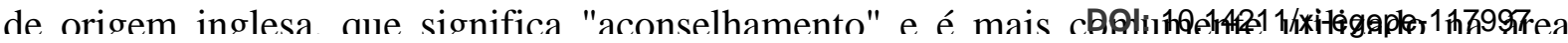


clínica, no sentido de aconselhamento médico ou psicológico, embora, atualmente, o termo 'aconselhamento' venha sendo utilizado de forma similar ao de mentoring ou coaching.

No Counseling, a interação entre Counselor (orientador de carreira) e o aconselhado é distante e selecionada por competência técnica e visão de mercado. $\mathrm{O}$ aconselhado busca um profissional que possa rapidamente treiná-los para lidarem com uma situação de crise, com uma oportunidade profissional inesperada, ou outra situação não programada, mas que gere alto impacto em sua tomada de decisão de carreira (CALVOSA, 2017).

As sessões poderão ser realizadas presencialmente ou na modalidade à distância, em um cenário formal e profissional. Nas sessões busca-se clarificar algum ponto que poderia estar obscuro do ponto de vista do aconselhado, gerar mais opções e cenários que o aconselhado não observou ou mesmo, dar uma contribuição com uma visão de mercado comercial ou organizacional, que tenha alto impacto no setor (CALVOSA, 2017).

O Counseling é um processo de desenvolvimento ou de intervenção onde conselheiros se concentram nos objetivos dos seus clientes. Assim, o aconselhamento envolve tanto a escolha quanto a mudança e em alguns casos, "o aconselhamento é um ensaio para a ação" (CASEY; GAIL, 1996, p. 176).

Minor (2001) apud Ferreira (2008) apresenta as diferenças entre Counseling e Coaching que poderão ser observadas no Quadro 4.

\section{Quadro 4: Diferenças entre Counseling e Coaching}

\begin{tabular}{|c|c|}
\hline COUNSELING & COACHING \\
\hline $\begin{array}{c}\text { Produtividade maior quando os empregados se } \\
\text { sentem ouvidos }\end{array}$ & $\begin{array}{c}\text { O trabalho do gestor é facilitado quando os empregados } \\
\text { estabelecem seus níveis de habilidade }\end{array}$ \\
\hline $\begin{array}{c}\text { Rotatividade reduzida quando os empregados sentem } \\
\text { que podem expressar suas ideias e sentimentos }\end{array}$ & $\begin{array}{c}\text { Permite maior delegação e, por conseguinte, mais tempo } \\
\text { para gerenciar versus "fazer por" }\end{array}$ \\
\hline $\begin{array}{c}\text { Prevenção contra resistência ou problemas após } \\
\text { mudanças }\end{array}$ & $\begin{array}{c}\text { Reconhecido como responsável pelo desenvolvimento de } \\
\text { pessoas }\end{array}$ \\
\hline $\begin{array}{c}\text { Eficiência superior quando há compressão sobre os } \\
\text { motivos, as necessidades e as reações dos } \\
\text { empregados }\end{array}$ & $\begin{array}{c}\text { Produtividade aumenta quando os empregados sabem } \\
\text { quais são as metas e como alcançá-las }\end{array}$ \\
\hline $\begin{array}{c}\text { Reduz o conflito e preserva autoestima } \\
\text { Melhora do preciso decisório quando diferentes } \\
\text { opiniões são ouvidas; pontos fortes e aptidões dos } \\
\text { empregados são complementados }\end{array}$ & $\begin{array}{c}\text { O reconhecimento positivo e o feedback aumentam a } \\
\text { motivação e a iniciativa dos empregados }\end{array}$ \\
\hline $\begin{array}{c}\text { As oportunidades profissionais melhoram quando o } \\
\text { gestor é conhecido como capaz de motivar os } \\
\text { empregados e gerar relações de trabalho construtivas }\end{array}$ & $\begin{array}{c}\text { Aumenta a probabilidade de as tarefas serem cumpridas } \\
\text { com qualidade; evita surpresas e a p; evita surpresas e a } \\
\text { postura defensiva nas avaliações de desempenho }\end{array}$ \\
\hline $\begin{array}{c}\text { O autoconhecimento, autoconfiança e a satisfação } \\
\text { pessoal aumentam no trabalho }\end{array}$ & $\begin{array}{c}\text { A criatividade e a inovação dos empregados aumentam } \\
\text { com o sentimento de segurança em assumir riscos }\end{array}$ \\
\hline
\end{tabular}

Fonte: Ferreira (2008, p. 17).

\subsection{Startup}

As startups que são empresas que têm como objetivo desenvolver um modelo de negócio, onde são observadas pessoas trabalhando em condições de extrema incerteza, para crescer rapidamente com altos ganhos.

O conceito de startups teve origem nos EUA e o termo foi popularizado nos anos de 1990, durante a alta nas ações das empresas chamadas 'ponto com', quando um grande número de empresas foi criado. Nesta época, muitos empreendedores apresentavam suas ideias inovadoras e encontravam muitos investidores para financiar o projeto e neste contexto, estas

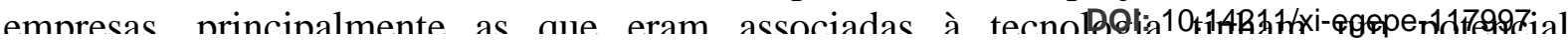


Silício (Silicon Valley) foi o local onde essas empresas apareceram e de onde saíram grandes representantes de novos modelos de negócios como o Google, Yahoo, Apple, Facebook, Twitter, Instagram entre outros (BLANK, 2012).

Nas últimas décadas várias definições sobre o termo 'startup' têm sido utilizadas para retratar essa nova fase do empreendedorismo digital e serão apresentadas no Quadro 5.

\section{Quadro 5: Conceitos e definições contemporâneas de startup}

\begin{tabular}{|c|c|}
\hline AUTOR/ANO & DEFINIÇÃo \\
\hline $\begin{array}{c}\text { Hermanson } \\
(2012)\end{array}$ & $\begin{array}{c}\text { Startup significa empresas de pequeno porte, que são recém-criadas ou ainda estão em fase de } \\
\text { constituição, e têm atividades ligadas à pesquisa e desenvolvimento, cujos custos de } \\
\text { manutenção sejam baixos e ofereçam a possibilidade de rápida e consistente geração de lucros. }\end{array}$ \\
\hline $\begin{array}{c}\text { Alves } \\
(2013, \text { p. 10) }\end{array}$ & $\begin{array}{c}\text { Startup é uma empresa iniciante com um modelo inovador, que atua em um cenário de } \\
\text { incertezas e busca o maior lucro possível em um menor tempo possível. As startups atraem } \\
\text { capital de risco, devido ao cenário de incertezas, a maioria possui base tecnológica inovadora } \\
\text { vinculada à internet. }\end{array}$ \\
\hline $\begin{array}{c}\text { Blank } \\
(2012, \text { p. 17) }\end{array}$ & $\begin{array}{c}\text { Uma startup é uma organização temporária projetada para buscar um modelo de negócio } \\
\text { escalável, repetível e lucrativo. }\end{array}$ \\
\hline $\begin{array}{c}\text { Ries } \\
\text { (2012, p. 24) }\end{array}$ & $\begin{array}{c}\text { Uma startup é uma instituição humana projetada para criar novos produtos e serviços sob } \\
\text { condições de extrema incerteza... "simplesmente faça" (p.45). }\end{array}$ \\
\hline $\begin{array}{c}\text { ABSTARTUPS } \\
\text { (2018) }\end{array}$ & $\begin{array}{c}\text { As Startups sempre dão um passo a mais na curva de aprendizado e mostram caminhos para } \\
\text { problemas novos e antigos e mais startups significam mais empregos, mais oportunidades e } \\
\text { mais desenvolvimento. }\end{array}$ \\
\hline $\begin{array}{c}\text { Cardoso } \\
\text { (2016. p. 2) }\end{array}$ & $\begin{array}{c}\text { As startups fazem parte de um recente modelo de empreendedorismo que têm chamado a } \\
\text { atenção no mercado, tanto das empresas privadas e públicas, universidades e investidores, pois } \\
\text { ambos enxergam no modelo de negócios das startups um modo inovador de empreender. }\end{array}$ \\
\hline
\end{tabular}

Fonte: Elaborado pela autora (2018).

Segundo Cardoso (2016), Leite e Barreto Junior (2013) em relação à realidade da gestão de startups, muitas não possuem clareza quanto às atividades dos empregados e aos processos de tomadas de decisão, havendo o controle de maneira informal e por isso; as startups dificilmente podem ser vistas como organizações formais.

Essa extrema incerteza se dá por não estarem relacionadas a um plano de negócio que objetiva sua viabilidade conforme indicadores financeiros, como rentabilidade, lucratividade e taxa de retorno sobre investimento. As startups sim criam a proposta de valor e arriscam fortemente na captura desse valor subvertendo a administração clássica (RIES, 2012).

Pode-se verificar que as startups são empresas que possuem duas características bem evidentes, a inovação e a incerteza e estas, estão intimamente ligadas aos impactos causados pela globalização e às transformações que ocorrem pela tecnologia.

É importante para o sucesso de uma startup, a criação do modelo de negócio contando com o conhecimento das condições e histórico de vida dos empreendedores, visto que o contexto das mesmas é incerto, e a experiência dos empreendedores é algo muito relevante. Para uma startup é importante ter a clareza do modelo de negócio, pois dessa forma conseguese priorizar as ações para o momento correto visando adequar a jornada de descoberta do cliente (BLANK; DORF, 2014).

Cardoso (2016) afirma que diante do panorama de inovação tecnológica que vêm criando força no mercado, com a participação de um público jovem torna-se relevante pesquisar de sobre as startups e seu modelo de negócio tão distinto do modelo tradicional utilizado no passado, onde a construção de uma carreira sólida só poderá ocorrer com o compartilhamento das exneriências de um mentor DOI: 10.14211/xi-egepe-117997 


\section{MÉTODO}

Trata-se de uma pesquisa exploratória, qualitativa e como método optou-se pelo levantamento qualitativo de dados, condizente com o questionamento apresentado no capítulo introdutório. Para Minayo (2002) a pesquisa qualitativa trabalha com o universo de significados, motivos, aspirações, crenças, valores e atitudes, o que corresponde a um espaço mais profundo das relações, dos processos e dos fenômenos.

A pesquisa de campo foi realizada através de entrevistas semiestruturadas com dois grupos, atores no processo de mentoria: Grupo 1 formado por Mentores e Grupo 2 formado por mentorados em instituições de fomento, aceleradoras ou incubadoras. Optou-se pelos dois grupos para se obter uma visão ampla dos envolvidos no processo de mentoria. Para a realização das entrevistas foram desenvolvidos dois roteiros utilizados como instrumento para a pesquisa, sendo que os mesmos foram pré-testados antes de sua aplicação. Foram entrevistados 12 (doze) mentores e 12 (doze) mentorados. As entrevistas aconteceram de forma presencial e tiveram duração de cerca de 20 (vinte) minutos.

Após a realização das entrevistas, as mesmas foram transcritas de modo a elaborar um quadro analítico que facilitou a análise dos achados, através da análise de conteúdo. A análise de conteúdo, segundo a perspectiva de Bardin tem sido uma das técnicas mais utilizadas para esse fim (GODOY, 1995).

As etapas para análise de conteúdo segundo Bardin (1977) podem ser visualizadas na Figura 2. Na presente pesquisa, os passos para a realização da análise de conteúdo foram: (i) Pré-análise; (ii) Exploração de Material e o Tratamento dos resultados; e (iii) Interpretações.

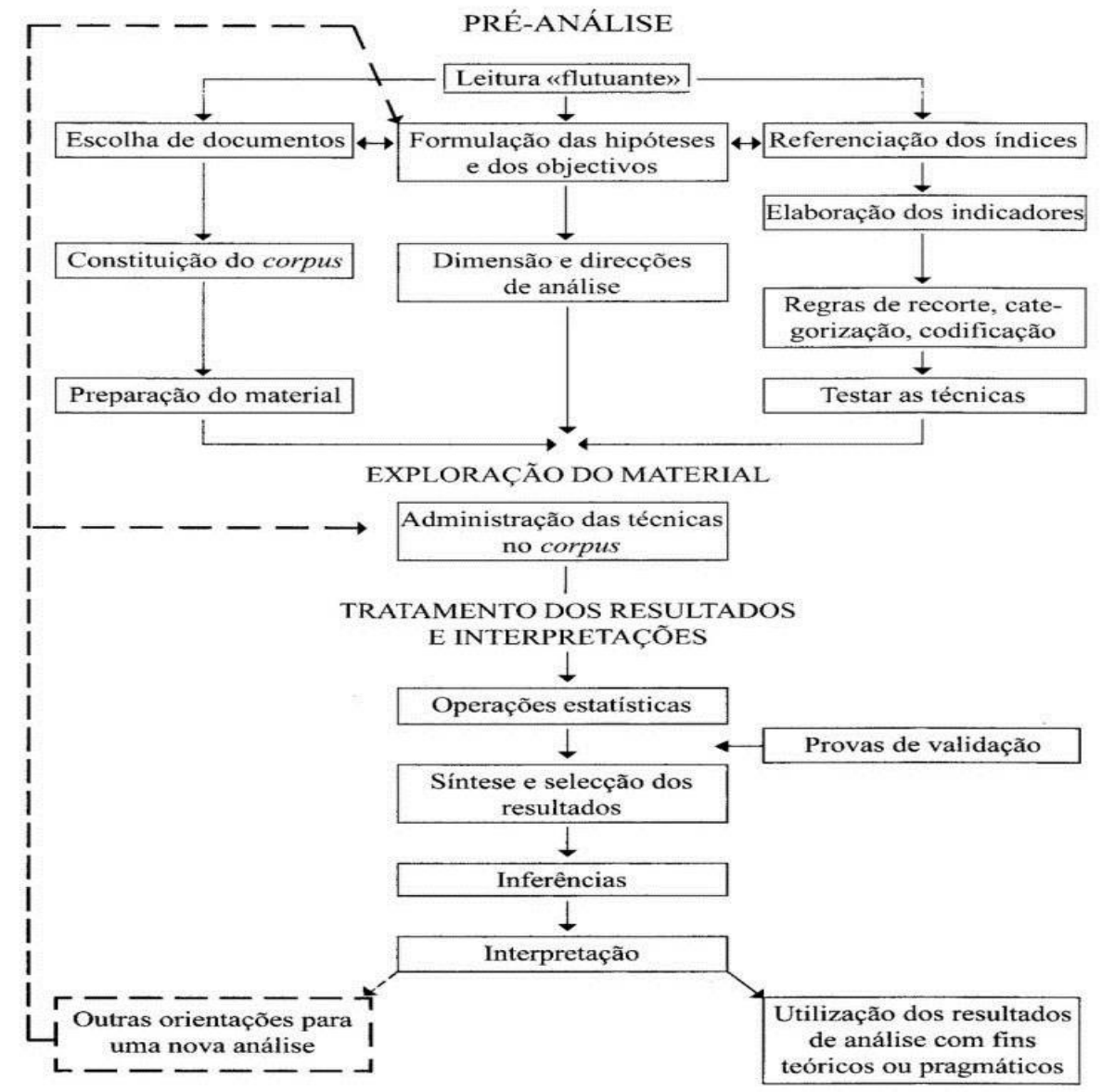

Figura 2: Etapas da Análise de Conteúdol: 10.14211/xi-egepe-117997 
A fase da pré-análise foi realizada com a transcrição dos áudios das entrevistas realizadas com os mentores e mentorados. Foram realizadas todas as transcrições das entrevistas e selecionados os trechos de relevância. Na fase de exploração do material as informações foram consolidadas em categorias (Quadro 6) e unidades de contexto (Quadro 7). E na fase de tratamento dos resultados foi feito o tratamento dos resultados brutos, de modo a que sejam significativos para a problemática em estudo.

Quadro 6: Especificação de Categorias de Análise - Mentores/Mentorados

\begin{tabular}{|c|c|}
\hline ITEM & CATEGORIAS DE ANÁLISE \\
\hline A & Definição de Mentoria Spot \\
\hline B & Vantagens da Mentoria Spot \\
\hline C & Desvantagens da Mentoria Spot \\
\hline D & Comparação do coaching, mentoring e counseling \\
\hline E & Desafios da Mentoria Spot \\
\hline F & Utilização da Metodologia Canvas \\
\hline G & Expectativas não satisfeitas na Mentoria Spot \\
\hline
\end{tabular}

A partir das transcrições das entrevistas obtidas junto aos entrevistados, com base nos objetivos e categorias de análise propostas, foram agrupados os dados obtidos que compõem o Quadro 7, o qual serviu de base para a elaboração do Framework.

\begin{tabular}{|c|c|}
\multicolumn{1}{c}{ Quadro 7: Operacionalização } \\
\hline ITEM & UNIDADES DE CONTEXTO \\
\hline A & Objetivos/Definição \\
\hline B & Problemas levantados \\
\hline C & Localidade/infraestrutura \\
\hline D & Duração/Tempo \\
\hline E & Resultados esperados \\
\hline F & Procedimentos \\
\hline G & Custos \\
\hline H & Avaliações/Correções \\
\hline
\end{tabular}

\section{RESULTADOS}

Para a apresentação dos resultados obtidos com a pesquisa de campo, cabe a apresentação do perfil dos respondentes.

Verificou-se que a maioria dos entrevistados mentores se apresentam na faixa etária de 25 a 55 anos, sendo que 58\% são homens. Em relação ao tempo de atuação como mentores, um terço dos entrevistados tem mais de 5 (cinco) anos de experiência em mentorias.

Sobre os mentorados percebeu-se que a maioria dos entrevistados estão na faixa etária de 32 a 38 anos, sendo que 58\% são mulheres e $67 \%$ das startups estão na fase de crescimento. Em relação ao tempo no mercado, $67 \%$ das startups estão atuando no mercado há pelo menos até dois anos, ou seja, são muito jovens.

\subsection{Sobre as mentorias spot}

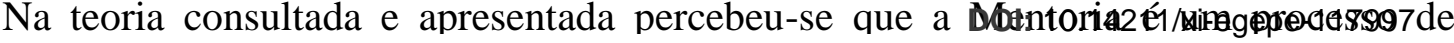


um mentor; que é uma pessoa mais experiente, que na prática, o acompanha, dando-lhe uma espécie de aconselhamento baseado em reflexões e transferência de experiências, com a intenção de deixar o mentorado mais apto, qualificado e motivado em sua jornada de desenvolvimento pessoal e profissional.

O conceito de mentoria spot é ainda mais vago e desconhecido pelo grupo de respondententes mentorados. Com relação aos entrevistados do grupo de mentores percebeu-se que eles têm conhecimento prévio, corroborando assim com os estudos apresentados por Kram (1988) e Campos, Capelle e Silva (2017).

Essa percepção vai ao encontro de trabalhos como os de Calvosa (2013), Cruz et al. (2012) e Lima, Silva, Calvosa (2008), nos quais não tratam o termo mentoria spot de forma direta, mas o seu conceito aparece disperso no conteúdo da pesquisa, quando aborda o processo de orientação profissional, o desenvolvimento pessoal e profissional, além de planejamento estratégico pessoal, apresentando significados consoantes com a pesquisa de mentoria spot.

Trata-se de um conceito de mentoria que diverge, ligeiramente, do tradicional, sempre mais filosófico, abrangente, sem a pressão de sessões finitas e a obrigatoriedade de uma ação ou resultados esperados. O conceito prático desenvolvido por Calvosa (2013), Cruz et al. (2012) e Lima, Silva e Calvosa (2008) está próximo ao conceito de mercado aplicado ao objeto de observação dessa pesquisa e utilizado no SEBRAE, ou seja, em sendo um processo singular, que se avaliou posicionar entre um processo de coaching tradicional e um processo de mentoria tradicional, possuindo alguns traços de ambos, mas com suas peculiaridades e modelagem própria.

Assim, na pesquisa de campo realizada percebeu-se que o conceito de mentoria spot ainda é vago para os mentores e desconhecido pela maioria dos mentorados.

\subsection{Sobre a operacionalização das mentorias spot}

Os principais desafios citados pelos mentores sobre as mentorias spot são os aspectos relacionados ao tempo da mentoria. Essa questão também apareceu ao serem questionados sobre vantagens e desvantagens, o que pode levar a inferência de que o tempo é uma variável importante para os mentores.

$\mathrm{Na}$ literatura pesquisada não foi mencionado aspectos relacionados à duração ou ao tempo ideal para o processo de mentoria spot.

O principal desafio citado pelos mentorados é o mentor conhecer previamente sobre os aspectos dos negócios dos mentorados, para se economizar tempo nas mentorias, quando o mentorado o que evitaria de se ter que apresentar todo o negócio ao mentor. Um outro desafio apontado pelos entrevistados mentorados em relação a mentoria pontual é o curto período de tempo para a sua realização, com efetividade e o conhecimento e entendimento prévio do negócio, por parte do mentor, para ajudar, com rapidez, o mentorado em suas questões pontuais.

Tal achado corrobora com os achados do grupo de mentores e com os estudos de Pereira (2016) que afirma que a atuação do mentor poderá ser decisiva para o sucesso do empreendedor que poderá ter as suas necessidades atendidas de forma rápida e pontual; pois o mentor possui conhecimento e legado intelectual.

A maioria dos mentores consideram ruim a falta de acompanhamento após o processo da mentoria spot de forma a se avaliar a efetividade do processo. Tal achado pode ser relacionado com a importância destacada por Vergara (2012) sobre a eficiência da mentoria, que requerer a observância de determinados comportamentos por parte do mentor e do mentorado; onde espera-se que o mentorado tenha disponibilidade psicológica e espiritual para a aprendizagem; mas por outro lado há casos de mentores com inúmeras dificuldades em relação à operacionalização do ambiente de trabalho, à execução das tarefas e à compreensão

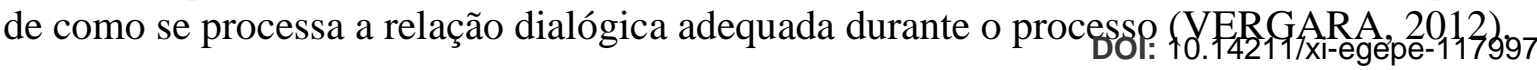


Após verificar os dados primários da operacionalização das mentorias spot no universo das startups, no que concerne as fases de sua execução, propõe-se no Quadro 8 a apresentação de um framework com as fases da mentoria spot baseado na ferramenta de Qualidade $5 \mathrm{~W} 1 \mathrm{H}^{1}$.

Quadro 8: Framework com as fases da mentoria spot

\begin{tabular}{|c|c|c|}
\hline FASES & MOMENTO & DESCRITIVO \\
\hline 1 & O que & $\begin{array}{l}\text { Quais são os objetivos da mentoria? O que será feito? Avaliar a existência de uma } \\
\text { definição clara do escopo do projeto. Qual atividade precisa ser realizada? }\end{array}$ \\
\hline 2 & Por que & $\begin{array}{l}\text { Quais os problemas enfrentados? Por que será feita a mentoria? Efetuar um } \\
\text { levantamento sobre os motivos para o estabelecimento da mentoria, avaliando o } \\
\text { histórico do problema, identificando e priorizando as causas raízes dos } \\
\text { problemas. Por que a atividade deve ser realizada? }\end{array}$ \\
\hline 3 & Onde & $\begin{array}{l}\text { Onde será realizada a mentoria? Avaliar a infraestrutura do local onde ela } \\
\text { ocorrerá. Qual a disponibilidade de recursos humanos, materiais e financeiros? }\end{array}$ \\
\hline 4 & Quando & $\begin{array}{l}\text { Qual o tempo disponível para a mentoria? Quando será realizada? Em qual } \\
\text { período? }\end{array}$ \\
\hline 5 & Para que & $\begin{array}{l}\text { Quais são os resultados esperados com a mentoria? Estabelecer critérios para } \\
\text { mensurar os benefícios alcançados qualitativa e quantitativamente. }\end{array}$ \\
\hline 6 & $\begin{array}{l}\text { Por quem e } \\
\text { para quem }\end{array}$ & $\begin{array}{l}\text { Definir quem são os atores envolvidos no processo (mentor, mentorado, empresa, } \\
\text { clientes, ofertas) participa das ações necessárias para desenvolver a atividade. }\end{array}$ \\
\hline 7 & Como & $\begin{array}{l}\text { Quais os procedimentos que serão adotados em cada etapa? Como a atividade } \\
\text { deve ser realizada para alcançar o objetivo? }\end{array}$ \\
\hline 8 & Quanto & Avaliar a viabilidade financeira do negócio. Quanto "custará" a atividade? \\
\hline 9 & Avaliar & $\begin{array}{l}\text { Deve-se analisar se os passos de cada etapa foram cumpridos: envolvendo a } \\
\text { análise dos fenômenos e do processo, conhecimento do estado atual do processo, } \\
\text { levantamento das causas potenciais do problema e análise quantitativa e } \\
\text { qualitativa. Deve-se elaborar medidas de avaliação do processo para corrigir } \\
\text { falhas e ou distorções. As ações propostas foram implementadas e foram eficazes } \\
\text { para a resolução do problema? Foi elaborado um novo Mapa de Processo? Foi } \\
\text { criado e implementado um plano de monitoramento e sustentabilidade dos } \\
\text { resultados? }\end{array}$ \\
\hline
\end{tabular}

\subsection{Apresentação da Mentoria Spot}

Tomando-se por base as definições apresentadas pelos mentores e mentorados na categoria A, pode-se definir a mentoria pontual como sendo: uma mentoria espontânea, desvinculada de um programa de acompanhamento, que traz conhecimentos que o mentor adquiriu ao longo do tempo para dar o direcionamento a uma empresa, principalmente para as startups, visando ajudar a resolução de problemas, guiando para uma possível solução. É uma mentoria ocasional, com momentos estabelecidos, com data de início e data de término, pautada em uma relação entre o mentor e a startup em tempo curto.

A relação mentor e mentorado deve ser uma relação de confiança profissional onde o mentor deve estabelecer um plano de ação, com um aprofundamento sobre o que é o negócio, as dificuldades e a falta de informações enfrentadas, para que assim, possa dar um direcionamento ao mentorado no processo da mentoria spot.

Seema e Sujatha (2014) afirmam que um dos muitos benefícios da orientação na mentoria é o aumento da satisfação no trabalho dos mentorandos, afetando positivamente o sucesso profissional do aprendiz. Existem muitas pesquisas, como as de Hezlett, Gibson, (2007), Pereira (2016) e Brito (2017) que exploraram os benefícios da orientação para mentorandos, descobrindo que a mentoria está altamente relacionada a importantes resultados de carreira, como nível salarial, taxa de promoção e emprego. Na presente pesquisa as 
vantagens e as desvantagens percebidas com a mentoria spot não são os mesmos percebidos pelo mentoring. De forma a sintetizar as vantagens e desvantagens elaborou-se o Quadro 9.

\section{Quadro 9: Vantagens e desvantagens das mentorias spot}

\begin{tabular}{|c|l|}
\hline \multirow{5}{*}{ Vantagens } & - Experiência específica do Mentor, possibilitando diferentes insights ao Mentor. \\
& - A aplicabilidade da mentoria em diversos segmentos. \\
& - A opinião e visão externas desvinculadas de equipe, com os insights que podem surgir. \\
& - A construção de um elo, da conquista de uma confiança. \\
- O empreendedor recebe em um curto espaço de tempo, as várias experiências & profissionais que os mentores trazem neste processo. \\
& - Atualização do mentor em relação ao mercado, devido a real necessidade de oferecer \\
& um feedback mais assertivo. \\
& - A troca de experiência bem rápida, profunda, o que acaba agregando muito para os dois \\
& lados (mentor e mentorado); e assim; ambos conseguem se conectar com mais pessoas, \\
& conhecendo novas situações e agregando mais conhecimentos. \\
& - Certa imparcialidade do mentor na mentoria spot. \\
\hline \multirow{5}{*}{ Desvantagens } & - Curto espaço de tempo pode fazer com que a mentoria spot não seja efetiva. \\
& - Existência de Mentores sem a qualidade adequada. \\
- Pode haver pouco engajamento de ambos os lados. \\
- Não há acompanhamento na evolução da empresa. \\
- Dependência do Mentorado para com o Mentor. \\
- Quando não há uma conexão e o empreendedor não escuta e não participa de mentoria, \\
não colocando em prática aquilo que foi trabalhado na melhoria. \\
- Na mentoria spot o mentor não acompanha a evolução da empresa.
\end{tabular}

Em relação a categoria "Expectativas não atendidas pela mentoria spot" foram apontados pelos entrevistados: a limitação de tempo, o modo de estruturar a mentoria spot, a expertise do mentor, desconhecimento dos resultados das ações de longo prazo, desconhecimento em como lidar com questões mais superficiais, a falta uma metodologia de feedback de expertise e acompanhamento do mentor e o modo de estruturar a mentoria spot.

\section{CONSIDERAÇÕES FINAIS}

A pesquisa contribuiu para tentar sanar a lacuna teórica acerca da conceituação e avaliação do processo de mentoria spot ao buscar responder a seguinte questão: O que é a mentoria spot no universo das startups?

Através das entrevistas pode-se constatar que o conceito de mentoria spot é vago e desconhecido para a maioria dos respondentes, sendo que a mentoria é um processo que pode demandar certo tempo, pois há muita informação que precisa ser passada, neste sentido, o mentor deve ser um profissional mais experiente que orienta o mentorado em reuniões préestabelecidas, com o acompanhamento que buscará sempre auxiliar o mentorado na conquista dos seus objetivos, mas como todo processo.

Após a realização da pesquisa teórica e empírica, pode-se considerar que mentoria spot é uma orientação pontual realizada por um mentor, no qual ele traz um conhecimento notório, um saber apontado pelos participantes do ecossistema das startups, como a melhor pessoa para ajudar o empreendedor/mentorado em um desafio específico e situacional.

Apesar do nome ser Mentoria Spot, após a pesquisa empírica, percebeu-se que a mesma tem características não condizentes com mentorias descritas na literatura, e também, não difere da ideia geral de mentoria dentro de organizações, sendo que as principais diferenças são: a questão da temporalidade; 'o curto espaço de tempo' e a questão da 'pontualidade'; restrição de temas, passando a ideia de perda de abrangência e desenvolvimento contemplativo.

O problema central da pesquisa foi respondido apontando que a mentoria spot pode ser usada como uma ferramenta eficaz em programas de treinamentol:el olesenmøledigpent Ф799таs, 
empírica sobre a sua conceituação e a avaliação do seu processo. Ou seja, apesar da mentoria spot estar presente na prática das instituições, ainda carece de estudos e conceitualização na teoria.

Um outro aspecto analisado foram os desafios das mentorias spot. Um deles, citado pelos mentorados, é o de que o mentor deveria conhecer previamente sobre os aspectos do negócio, porque há um curto período de tempo para a realização da mentoria, e muitas vezes os mentorados perdem parte do valioso tempo desse processo, tentando explicar aos mentores sobre o seu negócio. Por outro lado, percebeu-se que se houver efetividade, conhecimento e entendimento prévio do negócio, por parte do mentor, este poderá ajudar com rapidez o mentorado em suas questões pontuais. A maioria dos mentores entrevistados acham que há uma certa expectativa que não é atendida e que após a mentoria não há um acompanhamento, para se avaliar a efetividade do processo.

$\mathrm{Na}$ literatura pesquisada não foi mencionado aspectos relacionados à duração ou o tempo ideal para o processo de mentoria spot. Este é um ponto importante da mentoria que não ficou claro na pesquisa e que gera a necessidade de estudos futuros.

A pesquisa apresenta limitações, tanto de caráter metodológico como de caráter operacional. Em relação às limitações metodológicas há uma limitação natural imposta pelo próprio recorte dado à pesquisa, onde a análise dos dados se deu pela metodologia de análise de conteúdo proposta por Bardin (1977), mas esta não se configura como a única metodologia possível para análise de resultados de pesquisa qualitativa, deixando aberta uma gama de possibilidades.

Apesar do esforço de busca de referenciais teóricos, poucos são os estudos que voltam seus esforços para o entendimento da temática, o que faz com que haja, por um lado, uma restrição na apresentação do referencial, mas por outro, torna a atual pesquisa interessante academicamente, apesar de se tratar de uma pesquisa qualitativa, aplicada, de ordem prática e profissional.

Com a finalização deste estudo e sugerindo sua continuidade, a atual pesquisadora traz alguns insights: (i) na fase anterior à mentoria spot, o mentor deve receber e compartilhar informações da startup para o mentorado, e este deverá saber previamente quem será o seu mentor, buscando assim, informações que o ajudem a focar as suas dúvidas pontuais; (ii) durante a mentoria, o mentor deve se preocupar com a organização do tempo e com a metodologia a ser usada, buscando-se a efetividade no processo, que deverá envolver a disponibilidade em ouvir e compartilhar seus conhecimentos sobre o problema e a solução; e (iii) em seguida devem ser estabelecidas as formas de avaliar a efetividade do conhecimento trocado, havendo o levantamento das dificuldades do projeto, do tempo e do acompanhamento, durante e posterior a mentoria, junto ao mentor e mentorado.

\section{Referências}

ABREU, P.R.M; CAMPOS, N.M. O Panorama das Aceleradoras de Startups no Brasil. São Paulo: FGV, 2016.

ALVES, F.S. Um estudo das startups no Brasil: Universidade Federal da Bahia, Faculdade de Economia. Monografia (Graduação). Salvador: UFB, 2013.

ARANHA, J.A.S. Mecanismos de geração de empreendimentos inovadores: mudança na organização e na dinâmica dos ambientes e o surgimento de novos atores. Brasília, DF: ANPROTEC, 2016.

ARAÚJO, A. Coaching: Um parceiro para o seu sucesso. 4. ed. Rio de Janeiro: Elsevier. 2012. Associação Brasileira de Startups - ABS Startups. Por que Startups? Disponível em:

https://abstartups.com.br/sobre-a-abstartups/. Acesso em 28/08/2018: 10.14211/xi-egepe-117997 
BELLODI, P.L.; MARTINS M.A. Tutoria: mentoring na formação médica. São Paulo: Casa do Psicólogo. 2005.

BLANK, S. Entrepreneurship for the 21st Century. Business Models and Customer Development. Endeavor $\quad$ Brasil. 2012. Disponível em: https://dokumen.tips/download/link/design-thinking-business-model-canvasviaufscbrviaufscbrwp-contentuploads201702artigo-ciki-2015design2. Acesso em: 28/09/2018. BLANK, S.; DORF, B. Startup. Manual do Empreendedor. O Guia Passo a Passo para Construir uma Grande Empresa. Rio de Janeiro: Alta Books Editora, 2014.

BRITO, L.M.P. et al. Programa de mentoria: uma estratégia seminal de compartilhamento do conhecimento em uma empresa pública de energia. RACE, Revista de Administração, Contabilidade e Economia, Joaçaba: Ed. Unoesc, v. 16, n. 3, p. 209-234, 2017. Edição Especial.

CALVOSA, M. Indicadores para a Excelência na Formação dos Alunos de Administração e Obtenção de Alta Empregabilidade no Mercado. (Notas da Palestra). Projeto Desenvolvimento de Carreiras - Ciclo de Palestras para a Excelência Complementar na Formação e na Profissionalização dos Alunos e Comunidade Acadêmica na UFRRJ. UFRRJ, Seropédica, Rio de Janeiro. 24/08/2018.

Uso de Ferramentas Gerenciais na Gestão. (Notas da Palestra). Projeto Desenvolvimento de Carreiras - Ciclo de Palestras para a Excelência Complementar na Formação e na Profissionalização dos Alunos e Comunidade Acadêmica na UFRRJ. UFRRJ, Seropédica, Rio de Janeiro. 21/06/2017.

A Análise de Especialistas sobre o Modelo das Decisões Axiológicas: o equilíbrio e a sustentabilidade da tomada de decisão no processo de Planejamento Estratégico Pessoal. In: EnANPAD - Encontro da ANPAD, 2013, Rio de Janeiro. XXXVII ENANPAD, 2013.

CAMPOS, N.M. The myth of the idea: and the upsidedown startup. Charleston, SC: Createspace, 2015.

CAMPOS, N.; ABREU, P. O Panorama das Aceleradoras de Startups no Brasil. Escola de Administração de Empresas de São Paulo da Fundação Getúlio Vargas. Julho de 2016. São Paulo: FGV, 2016. D.O.I. 10.13140/RG.2.2.15025.79205.

CAMPOS, R.C.; CAPPELLE, M.C.A.; SILVA, T.M. Coaching: uma ponte no abismo relacional e gerencial em organizações. Revista Gestão em Análise, [S.1.], v. 6, n. 1/2, p. 287 299, dez. 2017.

CARDOSO, P.M. Os impactos dos programas de mentoria no desenvolvimento de startups. Artigo de conclusão do Curso de MBA em Gestão de Talentos e Comportamento Humano. Departamento de Administração, da Universidade Federal do Paraná. Curitiba, 2016. Disponível em: https://www.acervodigital.ufpr.br/bitstream/handle/1884/54132/R\%20$\% 20 \mathrm{E} \% 20-\% 20$ POLIANA\%20MARTINS\%20CARDOSO.pdf?sequence=1. Acesso em: 06/10/2018.

CASEY, J. GAIL F. F. A developmentalist who lives his ideas. The School Counselor, v.43, 1996. p.174-180.

CONSELHO REGIONAL DE ADMINISTRAÇÃO SÃO PAULO - CRASP. Resolução GEC/01 - 19/05/2009 CRA-SP. GEC - Grupo de Excelência em Coaching. Disponível em: http://crasp.gov.br/wp/wp-content/uploads/19_05_2009_Conceito_de_Mentoring.pdf. Acesso em $13 / 10 / 2018$.

COX, E.; BACHKIROVA, T.; CLUTTERBUCK, D. The complete handbook of coaching. London: Sage. 2014.

CUNHA, D.P.; DIAS, S.M.R.C. Mentoria Ideal x Modelo de Kram: Um caso brasileiro. Rio de Janeiro: XXXIV Encontro da ANPAD, 25 a 29 de setembro de 2010 Disponível em: 
CRUZ, A; LOPES, P; VILHENA, T; CALVOSA, M. Desenvolvimento Pessoal e Profissional de Futuros Gestores: como a Geração Y encara as competências necessárias para o aumento da empregabilidade e para o sucesso no ambiente profissional. In: Encontro da ANPAD, 2012, Rio de Janeiro. XXXVI ENANPAD, 2012.

FERREIRA, M.A.A. Coaching - um estudo exploratório sobre a percepção dos envolvidos: organização, executivo e coach. Dissertação (Mestrado). São Paulo: USP, 2008.

GODOY, A.S. Pesquisa qualitativa: tipos fundamentais. Rev. adm. empres., São Paulo, v. 35, n. 3, p.20-29, Junho de 1995.

HEZLETT, S.A.; GIBSON, S.K. Linking mentoring and social capital: implications for careers and organization development. Advances In: Developing Human Resources, [S.1.], 9, p.384412, 2007.

HIGGINS, M.C., KRAM, K.E. Reconceptualizing mentoring at work: a developmental network perspective. Academy of Management Review, v.26, $\mathrm{n}^{\circ}$ 2, 2001.

KRAM, K. E. Mentoring at work: developmental relationships in organizational life. Boston, EUA: University Press of America, 1988.

LEITE, G.S.L.; BARRETO JÚNIOR, M.L. Os Modelos de Desenvolvimento de Startups: Um Estudo de Caso em uma Empresa de Comércio Eletrônico. Projeto de Graduação. Rio de Janeiro: UFRJ. Escola Politécnica, 2013.

LIMA, R; SILVA, E.P.; CALVOSA, M. Uma Visão sobre Carreiras dentro da Estrutura Organizacional em Redes. Cadernos de Administração (Macaé), v. 1, p. 76-95, 2008.

MARQUES, J.R. Coaching: conceito e significado. IBC - Instituto Brasileiro de Coaching. 2018. Disponível em: http://www.ibccoaching.com.br/portal/coaching/coaching-conceitosignificado/. Acesso em: 12/12/2018.

MARQUES-LOPES, I. Coaching nutricional, un camino para conseguir cambios. Revista Española de Nutrición Humana y Dietética, [S.1.], v. 18, n. 1, p. 1-2, mar. 2014.

MASON, C.; ROSS B. Entrepreneurial Ecosystems and Growth Oriented Entrepreneurship. Paris: Organization for Economic Cooperation and Development. Oecd.org. January 2014.

MILARÉ, S. A.; YOSHIDA, E. M. P. Coaching de executivos: adaptação e estágio de mudanças. Psicologia: Teoria e Prática. 2007.

Intervenção breve em organizações: Mudança em coaching de executivos. Psicologia em Estudo, v. 14, n. 4, p. 717-727, 2009.

MINAYO, M.C.S. Pesquisa Social. Teoria, Método e Criatividade. $21^{\circ}$ Ed. Petrópolis: Editora Vozes, 2002.

MINOR, M. Coaching e aconselhamento: um guia prático para gerentes. Rio de Janeiro. Qualitymark, 2001.

OLIVEIRA NETO, C.C; SOUZA-SILVA, J.C. Aprendizagem, mentoria e cultura organizacional de aprendizagem: o estudo do caso da performance consultoria e auditoria. REAd. Rev. eletrôn. adm. (Porto Alegre), Porto Alegre, v.23, n.spe, p.6092, Dec. 2017.

PEREIRA, U.N.C. Empreendedorismo de alto impacto. Dissertação de Mestrado. Taubaté: Universidade de Taubaté. Departamento de Economia, Contabilidade e administração, 2016. PINHO, V.B. Orientação Profissional: Público-alvo, perspectivas de atuação e abordagens utilizadas. O Portal dos Psicólogos. Psicologia PT. 6 de julho de 2014.

RAGINS, B. R.; KRAM, K. E. The roots and meaning of mentoring. RAGINS, B. R.; KRAM, $\mathrm{K}$. E. The handbook of mentoring at work: theory, research, and practice. Thousand Oaks, CA: Sage Publications, 2007. p. 3-15. Disponível em: https://www.researchgate.net/publication/255662364_The_Handbook_of_Mentoring_at_Wor k. Acesso em: 29/08/2018.

RAMALHO, S.L. Coaching, Mentoring ou Counseling - Quå a melhor solucão para a 
http://www.administradores.com.br/artigos/marketing/coaching-mentoring-ou-counsellingqual-a-melhor-solucao-para-a-minha-realidade/44474/. Acesso em: 13/10/2018.

RIES, E. A Startup Enxuta: Como os empreendedores atuais utilizam inovação contínua para criar empresas extremamente bem-sucedidas. São Paulo: Leya Editora, 2012.

RICH, C. Writing and reporting news: a coaching method. [S.l.]: Cengage Learning, 2015.

SEBRAE. Like a boss. Ambiente Startups. 2018. Disponível em: http://www.sebrae.com.br/sites/Startup. Acesso em: 02/10/2018.

SEEMA, A.; SUJATHA, S. A Conceptual Framework of Mentoring on Career Success. IRJBM - Impact Factor. 7. 13-22. 2014. Disponível em: https://www.researchgate.net/publication/269106822_A_Conceptual_Framework_of_Mentori ng_on_Career_Success. Acesso em: 20/02/2019.

SHEA, G.F. Mentoring: Como desenvolver o comportamento bem-sucedido do mentor. Rio de Janeiro: Qualitymark, 2001.

SILVA, C.R.E. Orientação Profissional, mentoring, coaching e aconselhamento: singularidades Algumas em Práticas e semelhanças. Revista Brasileira de Orientação Profissional. 2010, v.11(2), 299-309, (julho-dezembro).

TAKAKI, L.A. Modelo de Desenvolvimento de Startups em Setores Tradicionais: um Estudo de Caso sobre a Maria Brigadeiro. Monografia. São Paulo: Insper, 2015.

UNESCO. Counseling. Module 2. Unesco Zambia. 1999. Disponível em: http://www.unesco.org/education/mebam/module_2.pdf. Acesso em: 07/01/2019.

VERGARA, S.C. Gestão de pessoas. 9. ed. São Paulo: Atlas, 2010.

. Mentoria: tutorial. Rio de Janeiro: FGV Online, 2012. 